Alicja Krzymowska-Kostrowicka

\title{
LANDSCAPE AS THE OBJECT OF INVESTIGATIONS. AN AXIOLOGICAL APPROACH
}

There are at least a dozen or so different definitions of landscape. Each of them is true and erroneous to some extent. This stems from the fact that landscape has many meanings. For example, it can be regarded as a set of more or less logically collected material objects with clear-cut or vague boundaries, or as a peculiar repertoire of the geographical, ecological, social and other roles, as a space of the meeting of functions - both manifest and hidden - combining the particular variables to form one entity; finally, as a source of psycho-physiological, aesthetic, cultural and other sensations. Thus, the choice of the point of view will always depend on the way in which landscape is investigated and evaluated.

The key problem in landscape evaluation is that of the selection of a model-pattern which would be at the same time common to different evaluation approaches, as well as separate enough, in order not to lose their specificity.

This is a preliminary attempt at classification of landscape evaluation approaches and it mainly points to different values of landscape as the evaluated object.

The system of landscape value can be divided into three principal groups: naturo-centric, anthropocentric and technocentric. Inasmuch as in the anthropocentric (or technocentric) assessment there is a relative separation of the evaluating subject from the evaluated object, in the naturo-centric evaluation this separation is being consciously blurred. Thanks to accumulated objective knowledge, man identifies himself with the evaluated object; he looks at reality from his point of view. Knowledge enables him to assess landscape as nature "sees" it, freed as much as possible from anthropomorphism or anthropo-centrism. The nature-centred approach should always take into account that "persistence of nature is its persistence in indifference towards man, according to its own laws..." (Kolbuszewski 1992, p.23). Thus, in evaluating landscape from the point of view of nature, one should free oneself from one's natural inclination to incor- 
porate natural phenomena into cultural schemes, being the source of anthropocentric and technocentric evaluation.

A general scheme of classification and typology of approaches to landscape values is presented in Fig.1. In order to explain the essence of the scheme, characteristics of the units distinguished will be discussed briefly.

\section{A. NATURO-CENTRIC VALUES}

1. Geocentric values. They are composed of the assessment of two different systems: non-biotic components of landscape and spatial structure. In the first case, the central point of the scale of values is a natural character of the mechanisms shaping non-biotic landscape environment, while in the latter - the character of the filling in of space, determining the capacity of the network of flow of the matter, energy and information.

2. Biocentric values. In this case, the principal evaluation criterion is the "good" of the living organisms (plants and animals), finding expression in the first place in optimization of the possibilities of reproduction, sufficient food supply etc.

3. Ecocentric values. The evaluation is based on efficiency of the functioning of ecological systems of the various ranks, determining their relative durability as well as the system of flow of the matter, energy and information, both within the individual system and among various ecosystems.

\section{B. ANTHROPOCENTRIC VALUES}

1. Psycho-physiological values. The criterion for evaluation in this case is the influence of both landscape as a whole, and of its components on human organism. These values can be divided into two sub-groups:

1.1. Psycho-stimulating values, combining the influence of the state and variables of landscape on man's mental life, finding expression in regulation of the functioning of the vegetative nervous system, liquidation of psychic tension etc.

1.2. Therapeutic values comprise the entire influence of the natural environment on somatic variables of human organism, on health in particular, with special reference to therapeutic properties of nature.

2. Cultural values. These values have been widely discussed both in scientific and popular literature. This specially applies to the relationship between "culture and nature". Cultural character of landscape, at least in our reality, is an established fact. Each European landscape is equally the work of nature and of culture; it is a peculiar "text" which cannot be read 


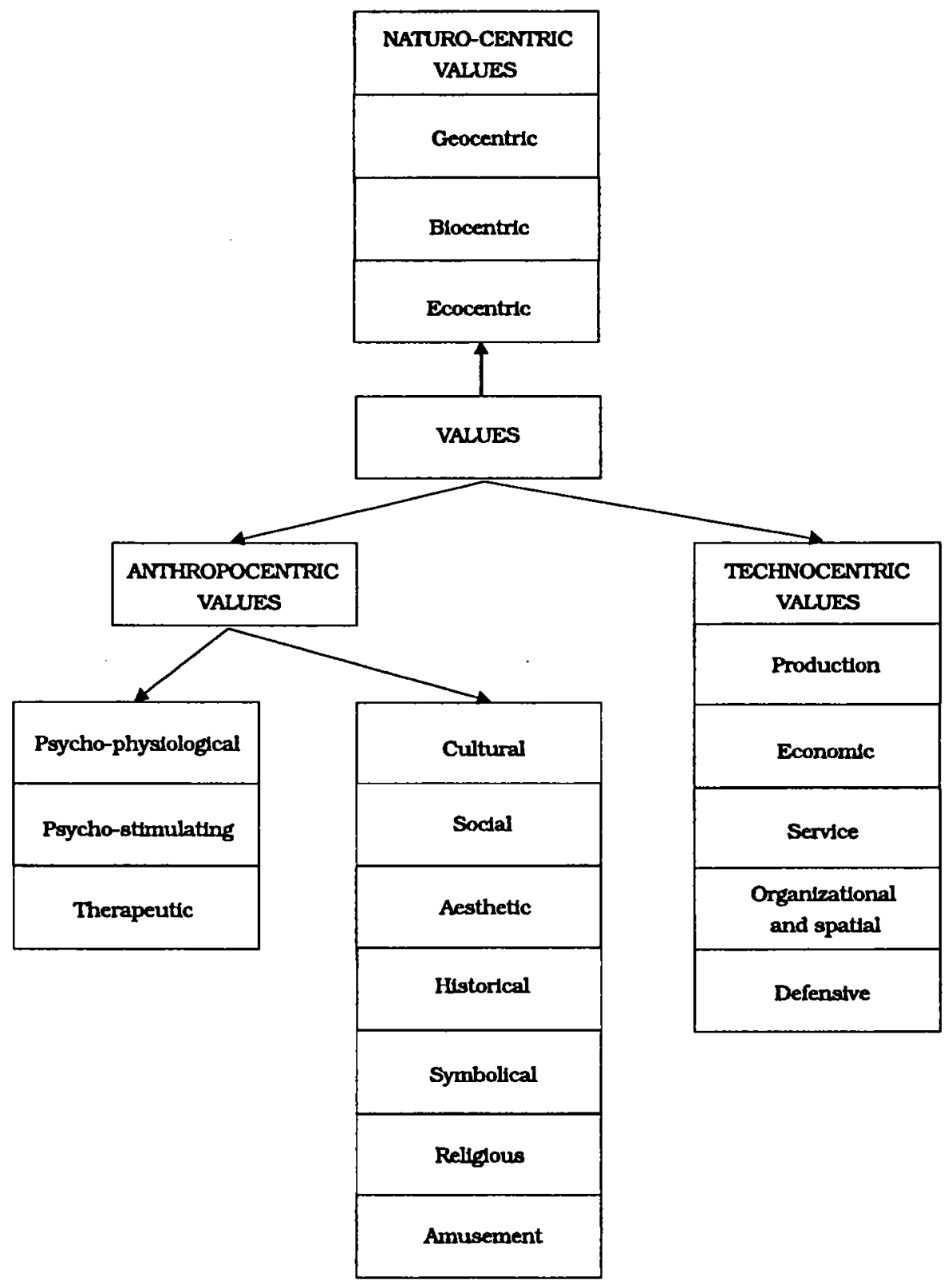

Fig.1. Classification scheme of landscape values 
unless one has a knowledge of its essence and of the evolution of this landscape.

Cultural value of landscape is a collective conception which is composed of the various ways of evaluation of the natural reality perceived which form separate sub-groups:

2.1. Social values. So far, they have not been studied either by natural sciences or sociology. However, they were thorougly investigated by cultural anthropologists who proved that the character of landscape, its structure and differentiation affect specificity of a number of social phenomena, such as, for example, the style of interpersonal communication, tendencies to organization of non-formal social groups, or the behavioural patterns.

2.2. Aesthetic values are most widely discussed in literature from among cultural values. Most attention has been paid to visual landscape values, although assessment of auditory or even smelling impressions have also been made.

2.3. Historical values concern both natural elements, which had been formed in the past and preserved in landscape to this day, and the elements of spiritual and material culture, being the evidence of the past.

2.4. Symbolical values of landscape are of specific character. They are a reflection of the old cultural archetypes, i.e. suggesting that nature has the meanings it never had (e.g. the names such as "Jungfrau", "Wotans Throne", or "Zoraster Temple"), definite mythical images preserved in culture (e.g. Olympus, Parnas etc.), or equally archetypal connotation such as "forest = tranquility, silence" and, finally, the so-called symbolical syntheses (e.g. Mazovian willows - Chopin), smartly used by the authors of advertisments. Sometimes, symbolical meanings may be so strong that they utterly veil reality.

2.5. Religious values are manifold. On the one hand, they are the effect of emotional-aesthetic and religious evaluation of sacred objects occurring in landscape; on the other hand, they express ecstatic-emotional human experiences, most often connected with the mountains or immesurable space.

2.6. Amusement values. This approach evaluates landscape as the place of entertainment, the term "entertainment" being understood widely. Not only as a place of games and festivities in the strict sense of the word but also as a field for sports activities, realization of individual hobbies (e.g. mountain-climbing, recording of voices of birds, observation of nature), or the realization of hedonistic needs.

\section{TECHNOCENTRIC VALUES}

In this case, valorization is made of the use of landscape for realization of the various economic and technical objectives. This group may be subdivided into: 
1. Production values, whose valorization is based on determination of real and potential functional usefulness of the terrain for various forms of its utilization, degree of investment in technical facilities serving the output, etc. This valorization is usually made in landscape studies directed towards agricultural or forest production.

2. Economic values. Their assessment stems from a number of factors, including the price of land, social pressure on the goods offered by landscape, degree of capital outlays etc. The basis for valorization is the spatial economic balance such as "costs - benefits" or "expenditure - results."

3. Service values of landscape encompass in the first place its usefulness from the point of view of establishment of a network of links (transport, energy, information etc.) between the particular technical objects occurring in landscape.

4. Organizational and spatial values. Landscape is evaluated in terms of its structure considered from the planning and spatial point of view, taking into account the occurrence of diverse barriers limiting the rational land management.

5. Defensive values. This type of evaluation used to be popular in the past. Two forms of landscape influence were considered: isolation and defensive. In the former case landscape was evaluated from the point of view of possibilities of separation - for various reasons - of both human groups and material goods; in the latter, from the point of view of the possibilities of their defence or security in the event of war.

A complex structure of landscape reality perceived, as well as specific social and personal conditioning of the observer cause that the creation of a certain objective system of sensorial evaluation of landscape is impossible. Thus, each approach was solely an approximation, the more so as the increasingly new landscape values mentioned previously may come to be predominant. Nevertheless, such attempts bring us closer to the understanding of the essence of the problem of evaluation of the reality perceived.

\section{REFERENCES}

Kolbuszewski J., 1992, Ochrona przyrody a kultura (Nature Protection and Culture), Wrocław, Wydawnictwo Uniwersytetu Wrocławskiego.

Krzymowska-Kostrowicka A., 1991, Zarys geoekologii rekreacji (The Outline c. Geo-ecology of Recreation), Warszawa, Warsaw University Press.

Richling A., Solon J., 1993, Ekologia krajobrazu (Landscape Ecology), Warszawa.

Ryszkowski L., Bałazy S., 1992, Wybrane problemy ekologii krajobrazu (S Issues of Landscape Ecology), Poznań, Wyd. Zakładu Badań Srodowiska Roh i Leśnego PAN.

Yi Tu a n, 1977, Space and Place. The Perspective of Experience, Minneapolis, $\mathrm{U}_{2}$. Minnesota Press. 
